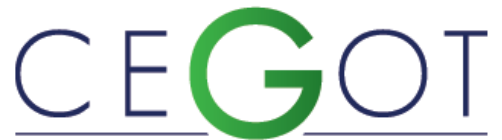

Centro de Estudos de Geografia e Ordenamento do Território
Geografia e Ordenamento do Território, Revista Eletrónica Centro de Estudos de Geografia e Ordenamento do Território http://cegot.org

FONSECA, SÉRGIO

Universidade Estadual Paulista "Júlio de Mesquita Filho", Faculdade de Filosofia, Ciências e Letras de Araraquara, Departamento de Administração

14800-901, Rodovia Araraquara-Jaú, km. 01, Araraquara-SP, Brasil saf@fclar.unesp.br

\section{LORENZO, HELENA}

Universidade de Araraquara, Programa de Pós Graduação em

Desenvolvimento Territorial e Meio Ambiente

14801-340, Rua Carlos Gomes, 1338, Centro, Araraquara-SP, Brasil

helenadelorenzo@gmail.com

RAMALHEIRO, GERALDA

Universidade de Araraquara, Programa de Pós Graduação em

Desenvolvimento Territorial e Meio Ambiente

14801-340, Rua Carlos Gomes, 1338, Centro, Araraquara-SP, Brasil

gee.cristina@gmail.com

\title{
A cooperação internacional para o desenvolvimento endógeno: experiência e lições do programa Brasil Próximo
}

International cooperation for endogenous development: experience and lessons from the Programa Brasil Próximo

Referência: Fonseca, Sérgio; Lorenzo, Helena; Ramalheiro, Geralda (2018). A cooperação internacional para o desenvolvimento endógeno: experiência e lições do programa Brasil Próximo. Revista de Geografia e Ordenamento do Território (GOT), n. ${ }^{\circ} 14$ (setembro). Centro de Estudos de Geografia e Ordenamento do Território, p. 221-224, dx.doi.org/10.17127/got/2018.14.008

\section{RESUMO}

Este artigo relata e avalia o percurso e os resultados de um programa de cooperação internacional descentralizada firmado entre o Governo Federal do Brasil e o Ministério das Relações Externas da Itália e que teve suas atividades conduzidas entre 2010 e 2015. Tomando como referência a literatura sobre as concepções contemporâneas de desenvolvimento local, o artigo aborda e problematiza os seguintes aspectos do Programa Brasil Próximo: a) a coordenação e a governança de um programa marcado essencialmente pela sua diversidade, multidisciplinaridade e descentralização; b) a efetividade dos resultados, tendo como base a materialização de evidências do desenvolvimento nos territórios objeto de intervenção do programa.

Palavras-chave: Desenvolvimento local; Cooperação; Experiências; Brasil Próximo.

\section{ABSTRACT}

This article reports on and evaluates the course and results of a decentralized international cooperation program signed between the Federal Government of Brazil and the Ministry of External Relations of Italy and conducted its activities between 2010 and 2015. Taking as reference the literature on contemporary conceptions of local development, the article addresses and problematizes the following aspects of the Programa Brasil Próximo: a) the 
coordination and governance of a program marked essentially by its diversity, multidisciplinarity and decentralization; b) the effectiveness of the results, based on the materialization of evidence of development in the territories subject to program intervention.

Keywords: Local development; Cooperation; Experiences; Brasil Próximo.

\section{Introdução}

As últimas duas décadas do século XX, sobretudo a partir das experiências empreendidas no contexto da chamada Terceira Itália, presenciaram o advento de novas concepções e adjetivações do conceito de desenvolvimento, como lembram Fischer (2002) e Potter et al. (2018, p. 7). As três versões adjetivas mais recorrentes do vocábulo (desenvolvimento territorial, desenvolvimento local, ou desenvolvimento endógeno, e desenvolvimento sustentável - que, de forma intencionalmente disseminada, substituiu, afirma-se aqui, com ressalvas, o conceito de ecodesenvolvimento) reúnem um conjunto de particularidades e características que, contrapostas à noção tradicional de desenvolvimento (Layrargues, 1997), agregam novos agentes e incorporam novas dimensões aos processos de promoção do desenvolvimento.

Embora diferentes matizes, ênfases e nuances tendam a distanciar, quando não a opor, as mencionadas três versões, alguns consensos as aproximam, como vêm evidenciando as várias correntes da literatura contemporânea. Um primeiro consenso, possivelmente o mais unificador, é o relativo à multidimensionalidade (Moreira \& Crespo, 2011). Contrapondo-se à ênfase estritamente econômica do desenvolvimento em sua acepção tradicional, autores como Lehtonen (2004), Scipioni, Mazzi, Mason e Manzardo (2009), Moulaert, Martinelli, Swyngedouw e Gonzáles (2005), Sachs (2002), Buarque (2008), Kashimoto, Marinho e Russef (2002), Saquet (2011), Soto (1997), Esparcia, Escribano e Serrano (2016) entre outros, guardando as suas respectivas visões particulares e diferenças de enfoques, defendem que a nova lógica de desenvolvimento abranja, de forma equilibrada, as esferas social, cultural, ambiental, espacial (ou territorial) e política (ou institucional), além da econômica, para assegurar melhorias na qualidade de vida. 
Um segundo aspecto, também amplamente reconhecido, é o relativo à importância crescente atribuída ao conhecimento, e às inovações dele oriundas (Albagli \& Maciel, 2004), como vetor de promoção desse novo estilo (ou paradigma) de desenvolvimento. As inovações, além de serem consideradas, por autores como Radas e Bozic (2009), Kaufmann e Tödtling (2002), Malecki (2007) e Moulaert e Nussbaumer (2005) como fatores de sobrevivência e competitividade dos agentes econômicos promotores da nova lógica de desenvolvimento (sobretudo dos empreendimentos de pequeno porte, adiante abordados), refletem e expressam os padrões de conhecimentos presentes nas esferas locais, sejam eles conhecimentos tácitos, guardando vínculos com as culturas locais e geradores de inovações de baixa complexidade (Grimpe \& Sofka, 2009; Heidenreich, 2009; Kirner, Kinkel \& Jaeger, 2009; Nunes, Serrasqueiro \& Leitão, 2012; Barge-Gil, 2010), ou ainda conhecimentos mais formais, emanados de universidades e centros de pesquisa instalados nos territórios e geradores de novos empreendimentos de base tecnológica (Rothwell, 1984; Hausman, 2005; Nooteboom, 1994). Redundante fica, pois, o reconhecimento do importante papel desempenhado pela universidade e pelos institutos de pesquisa como agentes indutores e apoiadores da nova concepção do desenvolvimento (Michael \& Beth, 2004; Mbah, 2016; Etzkowitz, 2004; Etzkowitz \& Leydesdorff, 2000; Mello, 2004).

Outra categoria definidora da nova lógica de desenvolvimento é a relativa ao estabelecimento de laços de atuação partilhada entre múltiplos agentes para oferecer impulso e sustentação aos processos endógenos de desenvolvimento. Partilhamento esse que pressupõe a constituição de redes de agentes (Castells, 1999; Muls, 2008; Andion, 2003; Frey, 2003) localmente articulados, atuando em cooperação (Marra, 2012; Fischer \& Melo, 2004, Farah, 2001), por meio da criação de estruturas e processos de governança (Tapia, 2005; Fischer \& Melo, 2004; Rover, 2011), fatores considerados de importância crítica para assegurar a sustentabilidade, no tempo, dos processos de desenvolvimento, como mostram Sobol (2008), Zanon (2014), Soto (1997) e Buarque (2008), entre outros.

Essa mesma característica de atuação partilhada, com seus condicionantes e desdobramentos acima pontuados, guarda dependência direta com a atuação do Estado (tratada aqui como a quarta categoria definidora do desenvolvimento em sua nova roupagem), notadamente em suas esferas subnacionais e marcadamente em países com baixa tradição de cooperação. Como observa Barquero (1995, p. 226), "é possível afirmar 
que os governos locais adquirem um papel de protagonistas na definição e na execução da política de desenvolvimento", posicionamento partilhado e complementado por Marra (2012, p. 255), ao registrar que o "poder de decisão é delegado a agências governamentais territoriais, assumindo-se que os agentes locais possuem tanto o conhecimento contextual como a legitimidade política para integrar diferentes medidas de política", notadamente em circunstâncias em que os governos locais se manifestam "dispostos a estabelecer processos públicos de participação e deliberação política" (Frey, 2003, p. 173). No Brasil, Farah (2001, p. 21) aponta que "o movimento em curso na esfera local pode ser entendido como parte de um processo de reconstrução da esfera pública, orientado para a democratização da gestão e das políticas públicas no país, o qual tem na descentralização um de seus componentes centrais". Em síntese e fazendo coro com esses e outros autores (Sienkiewicz, 2014; Silva, Babo \& Guerra, 2013; Amaral Filho, 2001) é possível afirmar e defender que o papel do Estado na esfera local, e das políticas públicas dele emanadas (com explícito incentivo e apoio à participação popular), represente fator crítico para o êxito de experiências de promoção do desenvolvimento em sua acepção contemporânea.

Os espaços territoriais concretos, demarcados por esse conjunto de categorias definidoras, econômicas, institucionais, políticas, culturais e sociais (Medeiros, 2016), acabam por se constituir em palcos de expressão de atividades econômicas que, de forma dialética, são favorecidas e potencializam essas próprias categorias.

Lugar de destaque é dado, pela literatura, aos empreendimentos de pequeno porte, sob variadas denominações e por múltiplas virtudes. Enfatizando essa relação dialética, Bianchi (1994) aponta para a convergência entre um padrão de desenvolvimento "não concentrado" e a proliferação e difusão das pequenas empresas. A potencialização desse papel das empresas de pequeno porte como agentes indutores do novo paradigma de desenvolvimento resultaria, sobretudo, de processos de aglomeração dessas empresas, capazes de gerar importantes economias externas. A literatura atribui diferentes denominações a esses processos de aglomeração, em conformidade com a maior ou menor presença de variáveis como: amplitude e complexidade das redes de agentes institucionais (públicos e privados) operantes no território; grau de cooperação entre as empresas; concentração ou dispersão setorial; intensidade tecnológica e difusão de inovações. Entre as denominações mais frequentes encontram-se as de: a) Clusters (Wood, Watts \& Wardle, 
2004; Sonobe \& Otsuka, 2015; Forsman, 2009; Olave \& Amato Neto, 2001), denominação que, mais recorrente na literatura internacional, também é apropriada por autores brasileiros, a exemplo dos dois últimos citados, sobretudo para fazer referência a aglomerações menos institucionalizadas e com predominância de empresas de setores tradicionais; b) Arranjos Produtivos Locais - APL's (Erber, 2008; Galdámez, Carpinetti \& Gerolamo, 2009; Noronha \& Turchi, 2005; lacono \& Nagano, 2007), denominação própria da literatura brasileira e que faz referência a uma vasta tipologia de aglomerações produtivas, porém tendo em comum a articulação entre múltiplos agentes e um certo grau de institucionalização; c) Sistemas Produtivos e Inovativos Locais (Costa, 2006; Campos, Cário, Nicolau \& Vargas, 2002; Cassiolato \& Szapiro, 2002; Lastres \& Cassiolato, 2003), conceito esse parcialmente correlato ao de APL, com as particularidades de inserir-se, na literatura, na tradição neo-schumpeteriana (sobretudo no que diz respeito à concepção de sistemas de inovação) e de, por consequência, colocar maior ênfase no papel das inovações notadamente as oriundas das tecnologias de informação e comunicação - como impulsionadoras e dinamizadoras dos arranjos implicados e das economias locais.

Deslocando-se o foco para setores de atividade particulares, com potencial de exercerem papel de protagonismo na promoção do desenvolvimento, configurado pelos parâmetros tratados neste artigo, embora a literatura ofereça espaço para uma grande diversidade de segmentos, a ênfase aqui será posta nos ramos da economia da cultura, da agricultura familiar e do turismo, por suas conexões com o objeto da pesquisa empírica.

Para tratar do papel e da importância da economia da cultura, necessário se faz registrar o fato de que, como lembra Burity (2007, p. 56), a partir dos anos 80 do século passado a diferença cultural passou a ser vista como "uma das trincheiras a partir das quais seria possível opor-se a modelos de desenvolvimento descontextualizados, desenraizados, sem lugar", orientando para a concepção de possibilidades alternativas de desenvolvimento. Mais adiante o mesmo autor aponta que "os projetos de desenvolvimento serão tanto mais eficazes nos contextos locais quanto mais respeitarem e dialogarem com a cultura do lugar" (p. 58), concluindo que "o lugar da cultura na eficácia das intervenções para o desenvolvimento ou para a realização de políticas públicas é algo irrecusável" (p. 59). Evidencia-se, pois, que 
o peso da cultura na economia vem através da identificação de como as atividades culturais, no sentido da produção artística, das manifestações folclóricas, da singularidade de certas comunidades ou da história de certos lugares poderiam ser incorporadas numa estratégia de desenvolvimento (Burity, 2007, p. 60).

O reconhecimento desse mesmo peso, e importância, da economia da cultura como fator de dinamização do desenvolvimento é partilhado por autores como Gorgulho, Goldenstein, Alexandre e Mello (2009), Reis (2007) e Lóssio e Pereira (2007), entre outros.

O segundo setor considerado para a abordagem neste texto, por suas virtudes como agente de promoção do desenvolvimento territorial e por sua presença intensa no contexto da pesquisa realizada, é o da agricultura familiar. Reconhecida por autores como Abramovay (1998; 2000; 2002 e 2007) Leite (2002; 2004), Bonnal e Maluf (2010) como um segmento produtivo que guarda em sua trajetória histórica importante papel no desenvolvimento econômico e social de países e regiões, a agricultura familiar é entendida como um conjunto de formas de produção que se opõem à agricultura empresarial, monocultora, "modernizada" e produtora de commodities. A agricultura familiar se expressa socialmente por formas de produção diversificadas, porém apresentando características comuns como a valorização do trabalho familiar e a autonomia da gestão dos meios de produção (Leite, 2002). Contudo, para além dos aspectos produtivos propriamente ditos, a agricultura familiar pode ser importante indutora do desenvolvimento local e territorial por sua multifuncionalidade e potencialidade para a integração entre os espaços rural e urbano, além dos âmbitos municipal e supramunicipal (Abramovay, 2007; Bonnal \& Maluf, 2009). Também atua no enfrentamento à pobreza, à desigualdade social e à insegurança alimentar (Bonnal \& Maluf, 2009), além de utilizar técnicas agrícolas de conservação dos recursos naturais e capacitar agentes para o processamento de produtos comercializados nos mercados locais (Santos \& Mitja, 2012).

De forma articulada, e guardando fortes sinergias com a economia da cultura e com a agricultura familiar, o turismo vem despontando contemporaneamente como uma das atividades mais dinâmicas em âmbito internacional (Barbosa, 2005), com um forte potencial de transformação e de valorização dos espaços locais. Como registra Almeida (2004, p. 1) "o lugar turístico existe em função da prática do turismo que lhe dá uma existência, uma identidade própria e singular". Não que essas transformações, ou a criação das novas identidades, sejam essencialmente virtuosas. Não são poucos os casos em que, como 
mostra Almeida (2004), os investimentos em grandes empreendimentos turísticos nos espaços locais, realizados por poderosos grupos econômicos, nacionais e internacionais, acabam por desfigurar e instrumentalizar os territórios em prol dos interesses dos investidores. O poder destrutivo sobre as culturas e os ecossistemas locais pode ser, como na maior parte das vezes o é, irreversível. Feita essa ressalva, defende-se aqui, como fundamento para a pesquisa realizada, a circunscrição e a delimitação dos tipos e perfis de atividades turísticas virtuosas, no que diz respeito à valorização dos lugares, sobretudo em suas dimensões cultural, social e ambiental (Cruz \& Pulído-Fernández, 2012; Blanco, 2004; Froehlich, 2000), como condição para a perenização, a longo prazo, do ambiente local para o turismo (Irving \& Sancho, 2005), o que remete ao reconhecimento de que essa condição seria alcançada por meio dos empreendimentos turísticos de pequeno porte.

Esse conjunto de referenciais, pontuados nesta seção introdutória (categorias definidoras do desenvolvimento em sua nova roupagem e setores de atividades considerados virtuosos) será utilizado como fundamento para a análise e a reflexão em torno de oito experiências e promoção do desenvolvimento local, levadas a cabo entre 2010 e 2014 em oito territórios brasileiros situados em estados de mesmo número.

Procurar-se-á, nas seções que seguem (a próxima, descritiva do Programa Brasil Próximo, a seguinte, apresentando e discutindo as ações e os resultados de cada um dos projetos regionais, a última tratando das conclusões e considerações finais) identificar e avaliar o percurso e os resultados de cada experiência, apontando-se a presença e importância relativa de cada uma das categorias definidoras, associadas aos respectivos segmentos de atividade.

Antes de dar prosseguimento aos relatos, contudo, são pertinentes breves comentários a respeito da estratégia e dos procedimentos metodológicos: a) no tocante ao método, a pesquisa enquadra-se como qualitativa, tanto por buscar extrair, relatar e interpretar as essências e as particularidades de cada um dos objetos investigados, quanto pelo envolvimento direto e pessoal dos pesquisadores com os ambientes de pesquisa; b) o delineamento da pesquisa é o de estudo de casos múltiplos; c) quanto ao propósito, reconhece-se que seja duplo, descritivo por retratar as características particulares de cada um dos objetos e exploratório pela incipiência do conhecimento relativo ao programa e aos projetos e pela impossibilidade de sua extrapolação; d) para a coleta dos dados foram 
utilizados instrumentos múltiplos, tais como a pesquisa documental, a observação direta, realizada pessoalmente pelos pesquisadores em visitas aos territórios dos projetos, as entrevistas, realizadas com base em roteiros semiestruturados, diretamente com múltiplos agentes vinculados a cada um dos projetos, em seus respectivos territórios; e) os dados foram transcritos, cruzados e interpretados por meio de técnicas de análise de conteúdo.

\section{O Programa Brasil Próximo como idealizador e gestor das intervenções nos territórios brasileiros}

As intervenções nos territórios objeto de avaliação neste artigo foram realizadas ao abrigo de um programa de Cooperação Internacional Descentralizada entre a Itália e o Brasil, denominado Programa Brasil Próximo. Financiado de forma partilhada pelos governos centrais italiano e brasileiro e pelas administrações locais dos municípios abrangidos, o Brasil Próximo patrocinou, em cooperação com cinco regiões italianas parceiras (Liguria, Emilia Romagna, Toscana, Marche e Umbria), um conjunto de ações orientadas para o desenvolvimento local de oito territórios (Mantiqueira - MG/SP, Alto Solimões - AM, Bagé RS, Centro Paulista - SP, Baixada Fluminense - RJ, Curitiba - PR, Campina Grande - PB e Serra das Confusões - PI), visando o fortalecimento econômico, a melhoria das condições sociais de vida e a preservação ambiental.

Como se tratam de territórios com realidades - econômicas, sociais, ambientais, culturais, institucionais e políticas - bastante díspares entre si, as modalidades das intervenções, do mesmo modo que os instrumentos de intervenção utilizados foram de variadas categorias. Algumas uniformidades, contudo, dão sentido de unidade ao programa como um todo em território brasileiro, com destaque para: o fortalecimento das micro e pequenas empresas; o reforço das competências e das capacidades das instituições locais; o apoio à construção de redes interinstitucionais; a capacitação técnica de agentes locais, públicos e privados; o incentivo à organização e à participação popular. Como se observa são princípios amplamente convergentes e condizentes com os principais pilares do desenvolvimento local, tais como abordados na seção introdutória deste artigo. 
Antes de prosseguir, contudo, na abordagem e relato das intervenções, julga-se pertinente tecer breves considerações a respeito da orientação mais geral do programa de cooperação. A literatura de cooperação internacional trata de duas orientações fundamentais de programas e projetos de cooperação (Douxchamps, 1996; Romero, 2010; Haftek, 2003). A primeira, predominante até os anos 80 do século passado, de recorte marcadamente vertical e caráter assistencial, implicando a transposição, aos países receptores da "cooperação", da lógica e dos instrumentos inerentes ao padrão tradicional de desenvolvimento (Potter et al., 2018, p. 6). Na segunda, que ganhou reconhecimento e disseminação após a última década do século XX, de caráter horizontal e descentralizado, adquire protagonismo a cooperação em seu sentido estrito (operação conjunta e partilhada) entre os agentes econômicos, sociais e políticos participantes do processo (dos países de ambas as esferas). Nessa última concepção os agentes "cooperantes" buscam estabelecer laços de estreita integração e articulação com as comunidades locais de cada um dos territórios (agentes "cooperados"), com vistas a aprofundar os conhecimentos a respeito das realidades locais para, a partir daí, formular as propostas de intervenções.

Esta última foi, precisamente, a concepção norteadora do Programa Brasil Próximo, tal como expressa na proposta de cooperação descentralizada submetida pelas regiões italianas da Úmbria, Marche, Ligúria, Emília Romagna e Toscana ao Ministero degli Affari Esteri e della Cooperazione Internazionale, da Itália em 2008, e aprovadas em 2010 (Brasil Próximo, 2008). Passo subsequente a proposta foi negociada com o governo federal brasileiro, que a acolheu.

Desdobrando-se o programa em seus respectivos projetos, as ações previstas (Brasil Próximo, 2008; 2016) estavam orientadas para as seguintes frentes de intervenções: políticas sociais; cooperativismo; apoio às micro e pequenas empresas; economia da cultura e do turismo; cadeia da madeira e móveis; consórcios intermunicipais e agências de desenvolvimento; energias renováveis e agricultura familiar.

Além de garantir uma intensa atividade de intercâmbio, formação e institutional building, o programa contribuiria para a realização dos planos de desenvolvimento dos territórios, por meio da identificação de setores estratégicos e possíveis alianças territoriais com a Itália. 
No que diz respeito aos perfis socioeconômicos dos territórios que foram objeto das intervenções, uma leitura preliminar permite classificá-los em dois grupos: de um lado, comunidades qualificadas e reconhecidas como de baixo índice de desenvolvimento, localizadas no Piauí, na Amazônia Ocidental e na periferia do Rio de Janeiro; de outro, regiões reconhecidas como detentoras de processos mais adiantados de desenvolvimento, com destaque para a da Mantiqueira, do Centro Paulista, de Curitiba e de Campanha, no Rio Grande do Sul (Lorenzo, Fonseca \& Sampaio, 2016). Em plano intermediário situou-se o território da Paraíba.

\section{As ações e os resultados dos projetos}

Para o relato e a reflexão em torno das ações realizadas e dos resultados alcançados nos contextos particulares de cada um dos projetos será adotado um referencial analítico apoiado em pressupostos da Teoria Geral dos Sistemas, notadamente pela suposta unidade do todo: o Programa, integrando e articulando as atividades das partes, os projetos. Essa opção analítica resultou da percepção de que, além da complexidade implícita, as ações em cada projeto foram alimentadas, induzidas, por um conjunto de estímulos emanados dos parceiros italianos - os inputs - que, uma vez absorvidos pelos agentes locais, se expressaram em ações de intervenção nos territórios - o processamento, orientadas para as transformações almejadas - os resultados (Neves \& Neves, 2006; Uhlmann, 2002). No plano empírico a pesquisa teve caráter qualitativo, desenhada como estudo de casos múltiplos, com o duplo caráter exploratório e descritivo. A coleta de dados foi realizada por meio de pesquisa documental, junto aos relatórios finais de avaliação de cada um dos projetos e relatórios finais da Secretaria-Geral da Presidência da República do Brasil e por visitas pessoais, a cada um dos projetos, pelos autores deste texto.

O projeto implementado na Baixada Fluminense (Estado do Rio de Janeiro) teve como foco as políticas sociais em um território abrangido por nove municípios, tendo como grupo focal a juventude e como atividade nucleadora a economia da cultura. A instituição executora local foi o Instituto Brasileiro de Análises Sociais e Econômicas (Ibase), em parceria com a ONG "Se essa rua fosse minha". As regiões italianas do Marche e da Toscana aportaram 
conhecimentos e apoios relativos à estruturação e implementação de iniciativas e projetos de cunho social. Entre os resultados alcançados deve ser dado destaque à criação do Observatório de Políticas Sociais para a Juventude, que realizou completo inventário de equipamentos e atividades culturais de grupos situados nos nove municípios da região, fortalecendo mais de 200 grupos culturais e criando condições para organizar e expandir políticas sociais para a juventude na região e para o fortalecimento da economia da cultura.

No Parque Nacional da Serra das Confusões (Estado do Piauí) as ações, centradas nos campos do turismo e da economia da cultura, abrangeram uma totalidade de 12 municípios. Tendo como executores locais as prefeituras dos municípios da microrregião e a Secretaria Estadual de Assistência Social e Cidadania, as atividades do projeto receberam supervisão técnica internacional da Região do Marche - responsável pela sensibilização, financiamento e relações governamentais - e da Região Toscana, que transferiu conhecimentos relativos à gestão de parques e reservas naturais. Os resultados obtidos se desdobraram nas seguintes frentes: criação e melhoria da infraestrutura para visitação turística ao parque; qualificação e treinamento de profissionais especializados em turismo de cultura; criação de um conselho intermunicipal de apoio ao turismo local.

Na região da Serra da Mantiqueira (Estado de Minas Gerais) o foco temático do projeto também foi no campo do turismo, com ações realizadas em doze municípios distribuídos entre os estados de Minas Gerais e São Paulo. As prefeituras de dois desses municípios assumiram a liderança na coordenação das ações do projeto, que teve como parceira internacional a Região Toscana, responsável pela transferência de conhecimentos sobre atividades turísticas e pela capacitação de profissionais locais para o exercício de funções afins. O principal resultado alcançado foi a criação da Associação de Desenvolvimento do Território da Mantiqueira (ADTM), congregando representantes da sociedade civil, empresários e agentes públicos municipais.

Na região Centro Paulista, o projeto, sob a coordenação e execução de três universidades regionais, teve como principal foco de intervenção o campo das micro e pequenas empresas, urbanas e rurais. Mediante o apoio da Região Úmbria a equipe executora acumulou conhecimentos e experiências que possibilitaram a realização de estudos comparativos sobre processos de desenvolvimento local e regional apoiados em redes de empreendimentos de pequeno porte e de cadeias curtas, com conteúdos de conhecimentos 
incorporados. Entre os principais resultados obtidos podem ser citados os apoios fornecidos a municípios da região para a implementação de políticas e ações de desenvolvimento local, apoiadas em empreendimentos de pequeno porte e articuladas com universidades e instituições de pesquisa regionais.

O quarto projeto, situado na região da Campanha, no entorno do município de Bagé, (Estado do Rio Grande do Sul) teve como foco a diversificação produtiva rural, apoiada na produção do azeite de oliva extravirgem em propriedades familiares de seis municípios. A Região Úmbria, em estreita parceria com a Empresa Brasileira de Pesquisa Agropecuária Embrapa-RS (principal executora do projeto, juntamente com a Prefeitura Municipal de Bagé), ofereceu forte apoio na transferência de conhecimentos técnicos sobre olivicultura e os correspondentes processos de extração e engarrafamento do óleo. Além da criação e consolidação de um pólo regional produtor do azeite - o primeiro do Brasil - o projeto propiciou, como resultado adicional, a criação da Associação de Olivicultores da Região da Campanha.

Em Curitiba (Estado do Paraná) o projeto esteve direcionado para o segmento de produção e comercialização de produtos agroalimentares, na Região Metropolitana de Curitiba. Com o apoio da Região Emilia Romagna - responsável pelo financiamento de parte das atividades do projeto e pela transferência de conhecimentos - os executores principais do projeto, Secretaria de Abastecimento do Estado do Paraná e Ceasa/Paraná, orientaram suas ações para estreitar as articulações entre produção e comercialização. Como resultado, alcançouse um patamar mais elevado de organização e cooperação entre os agentes dessa cadeia, com extensões para pequenos segmentos de agroindústrias de processamento e transformação dos produtos primários.

Na Paraíba, também com a assistência da Região Emilia Romagna, as ações do projeto ficaram restritas ao município de Campina Grande, com foco no segmento produtivo de fiação e tecelagem de manufaturados de algodão orgânico. Tendo como executores principais o SEBRAE regional e uma universidade instalada no município o projeto não alcançou resultados expressivos, conquanto tenha propiciado ganhos de imagem para os produtos à base de algodão orgânico. 
Na região Amazônica do Alto Solimões o projeto teve como focos o turismo ecológico e de aventura e o extrativismo "sustentável" de espécies madeireiras regionais, em nove municípios que compõem o Consórcio Intermunicipal da Mesoregião do Alto Solimões. Idealizado pela Diocese do Alto Solimões e coordenado pelo Fórum do Desenvolvimento do Alto Solimões, o projeto recebeu apoio internacional da Região Ligúria para a transferência de conhecimentos para a produção de artefatos de madeira e para a instalação de um complexo turístico. No plano interno os governos federal e estadual também ofereceram importantes apoios. Em termos dos resultados, merecem destaque particular a criação da Associação Igapó de Turismo e a instalação do Centro de Acolhimento e Orientação ao Turismo.

Esse conjunto de dados e informações fornecem elementos para uma síntese (contida no quadro 1), apoiada nos referenciais analíticos iniciais, relacionados na seção introdutória deste artigo.

A leitura cruzada dos resultados alcançados pelos projetos permite inferir, ao menos preliminarmente, a presença recorrente, em todos os projetos, de elementos suficientes para tratá-los como exitosos do ponto de vista da promoção do desenvolvimento, mesmo que em caráter transitório e limitado, nos territórios hospedeiros dos mesmos. São projetos que convergem, em diferentes escalas, com os princípios norteadores das concepções contemporâneas de desenvolvimento, em conformidade com os pressupostos apontados na seção introdutória deste artigo. 


\begin{tabular}{|c|c|c|c|c|c|}
\hline Projetos & $\begin{array}{l}\text { Natureza } \\
\text { temática do } \\
\text { projeto }\end{array}$ & $\begin{array}{l}\text { Presença de } \\
\text { conhecimento e } \\
\text { inovações }\end{array}$ & $\begin{array}{l}\text { Intensidade } \\
\text { de } \\
\text { cooperação }\end{array}$ & $\begin{array}{l}\text { Presença } \\
\text { do Estado }\end{array}$ & Setores \\
\hline $\begin{array}{l}\text { Baixada } \\
\text { Fluminense } \\
\text { (RJ) }\end{array}$ & $\begin{array}{l}\text { Cultural e } \\
\text { social }\end{array}$ & $\begin{array}{l}\text { Baixa } \\
\text { complexidade }\end{array}$ & Forte & Mediana & $\begin{array}{l}\text { Economia da } \\
\text { cultura }\end{array}$ \\
\hline $\begin{array}{l}\text { Serra das } \\
\text { Confusões (PI) }\end{array}$ & $\begin{array}{l}\text { Social, } \\
\text { cultural e } \\
\text { ambiental } \\
\end{array}$ & $\begin{array}{l}\text { Baixa } \\
\text { complexidade }\end{array}$ & Forte & Alta & $\begin{array}{l}\text { Turismo e } \\
\text { economia da } \\
\text { cultura }\end{array}$ \\
\hline $\begin{array}{l}\text { Mantiqueira } \\
\text { (MG) }\end{array}$ & $\begin{array}{l}\text { Econômica } \\
\text { e } \\
\text { institucional }\end{array}$ & $\begin{array}{l}\text { Baixa } \\
\text { complexidade }\end{array}$ & Forte & Alta & Turismo \\
\hline $\begin{array}{l}\text { Centro Paulista } \\
\text { (SP) }\end{array}$ & Econômica & $\begin{array}{l}\text { Alta } \\
\text { complexidade }\end{array}$ & Média & Baixa & \begin{tabular}{|l} 
Micro e \\
pequenas \\
empresas
\end{tabular} \\
\hline Campanha (RS) & Econômica & $\begin{array}{l}\text { Alta } \\
\text { complexidade } \\
\text { (técnica) }\end{array}$ & Forte & Mediana & $\begin{array}{l}\text { Agricultura } \\
\text { familiar }\end{array}$ \\
\hline $\begin{array}{l}\text { Curitiba } \\
\text { (PR) }\end{array}$ & $\begin{array}{l}\text { Econômica } \\
\text { e Social }\end{array}$ & $\begin{array}{l}\text { Baixa } \\
\text { complexidade }\end{array}$ & Forte & Mediana & $\begin{array}{l}\text { Agricultura } \\
\text { familiar e } \\
\text { Micro e } \\
\text { pequenas } \\
\text { empresas }\end{array}$ \\
\hline $\begin{array}{l}\text { Campina } \\
\text { Grande } \\
\text { (PB) }\end{array}$ & $\begin{array}{l}\text { Social e } \\
\text { econômica }\end{array}$ & $\begin{array}{l}\text { Baixa } \\
\text { complexidade }\end{array}$ & Fraca & Baixa & $\begin{array}{l}\text { Micro e } \\
\text { pequenas } \\
\text { empresas }\end{array}$ \\
\hline $\begin{array}{l}\text { Alto Solimões } \\
\text { (AM) }\end{array}$ & $\begin{array}{l}\text { Social, } \\
\text { ambiental e } \\
\text { econômica. }\end{array}$ & $\begin{array}{l}\text { Baixa } \\
\text { complexidade }\end{array}$ & Forte & Alta & $\begin{array}{l}\text { Turismo e } \\
\text { agricultura } \\
\text { familiar }\end{array}$ \\
\hline
\end{tabular}

Quadro 1 - Síntese e cruzamento das características essenciais dos projetos

Notas: Critérios utilizados para as classificações de intensidade de cooperação e presença do Estado.

1) Intensidade de cooperação: forte, quando múltiplos agentes operam no território de forma horizontal, permanente, articulada e integrada, sem qualquer supremacia individual; média, quando ocorrem articulações e interações entre agentes de forma esporádica e pontual; fraca quando a regra é um agente conduzir as atividades do projeto, sem a busca de parcerias como regra.

2) Presença do Estado: alta, quando assume (seja na esfera federal, estadual ou municipal) o papel de protagonista e dirigente do projeto; média, quando atua no contexto do projeto em pé de igualdade com os outros agentes ou de forma subordinada a um agente líder; baixa, quando se mantém distante das atividades do projeto.

Uma primeira constatação, sintetizada na segunda coluna do quadro, é a de que, embora a dimensão econômica tenha se mostrado presente em todos os projetos, sobressai em apenas dois deles e equilibra-se com outras dimensões no restante dos projetos. Mesmo nos dois projetos em que despontam em caráter de principalidade, componentes sociais 
encontram-se presentes como reguladores, expressos nos públicos alvos prioritários de cada um dos projetos, nominadamente segmentos de micro e pequenos empreendimentos, urbanos no caso do projeto Centro Paulista e rurais no da Campanha gaúcha. Outro indicativo passível de ser extraído dos dados dessa mesma coluna do quadro é que as características predominantes dos territórios, motivadoras dos respectivos projetos, tenham sido determinantes no estabelecimento das orientações prioritárias. Isso fica patente nos casos dos projetos da Baixada Fluminense e da Serra das Confusões, em que as marcantes fragilidades sociais acabaram por configurar os perfis fortemente sociais dos respectivos projetos. No contraponto, os três territórios com padrões econômicos mais elevados, Centro Paulista, Campanha gaúcha e Paraná tiveram as ênfases de seus respectivos projetos mais focadas na dimensão econômica. A mesma convergência foi observada nos casos dos projetos da Mantiqueira, Alto Solimões e Serra das Confusões, no que diz respeito à dimensão ambiental, uma vez que a preservação e a valorização dos ambientes naturais de cada um desses territórios são vistas como críticas para a própria sustentabilidade dos mesmos.

No que diz respeito ao papel dos conhecimentos e inovações como vetores de impulsão dos processos de desenvolvimento nos territórios, a pesquisa revelou que a maior parte dos projetos recebeu fortes e importantes aportes de conhecimentos dos parceiros italianos, tornados imprescindíveis para o desempenho de algumas das mais relevantes ações de cada projeto. Destacaram-se os seguintes conhecimentos aportados: fabricação de madeira e aqüicultura, no Alto Solimões; gestão de parques e reservas naturais, na Serra das Confusões; olivicultura e produção de azeites na Campanha; gestão de atividades turísticas, na Mantiqueira; fundamentos do associativismo e cooperativismo, no Paraná. Nos outros três territórios esse processo de transferência e absorção de conhecimentos não ocorreu: os conhecimentos relevantes foram aqueles já existentes nos próprios territórios, endógenos. Em termos tipológicos, os conhecimentos relevantes podem ser qualificados como: técnicos, nos casos do Alto Solimões e da Campanha; de gestão, nos casos da Serra das Confusões e da Mantiqueira; sociais, nos casos da Baixada Fluminense, Paraná e Paraíba; tecnológicos de baixa complexidade, no caso do Centro Paulista. Já no que concerne a inovações geradas, as mais evidentes foram as de caráter técnico na Campanha (em 
produtos e processos), as de gestão na Serra das Confusões, na Mantiqueira e no Paraná e as sociais, na Baixada Fluminense.

A constituição, valorização e fortalecimento de redes locais de agentes foi outra marca presente em todos os projetos, claro, com diferentes extensões, graus de coesão e formatos. Em escala de importância, no contexto do Programa Brasil Próximo como um todo, destaque deve ser dado aos casos dos territórios da Baixada Fluminense, Serra das Confusões, Mantiqueira e Campanha, nos quais as ações do Programa suscitaram na criação de institucionalidades novas, previamente inexistentes e que acabaram por assumir a governança das atividades de cada um dos projetos em seus respectivos territórios: Observatório de Políticas Sociais para a Juventude, na Baixada Fluminense; Pacto Intermunicipal, na Serra das Confusões; Associação de Desenvolvimento do Território da Mantiqueira; Associação de Olivicultores da Região da Campanha. No Alto Solimões e no Paraná foram fortalecidos e valorizados arranjos já existentes, como o Fórum do Desenvolvimento do Alto Solimões e associações e cooperativas no Paraná. Na Paraíba e no Centro Paulista não houve avanços significativos nesse campo.

Focando o papel desempenhado pelo Estado, em suas diferentes esferas, destaque deve ser dado, em primeiro lugar, ao Governo Federal que, por meio da Secretaria de Assuntos Federativos da Presidência da República, foi o idealizador, o negociador e o articulador do Programa como um todo, além de financiador de parte das ações. Em âmbito estadual, apenas os governos dos estados do Amazonas, do Piauí e do Paraná ofereceram apoios, institucionais e materiais aos respectivos projetos. Os demais se mantiveram distanciados. Nos planos municipais, as participações das administrações locais foram decisivas para o andamento das atividades dos projetos, à exceção da Paraíba (SEBRAE e UFCG como protagonistas) e do Paraná (papel de destaque para SEBRAE e Ceasa local).

Além desses resultados, o Programa Brasil Próximo representou uma oportunidade para os parceiros brasileiros debaterem questões importantes, tais como: a descentralização administrativa e participativa como impulsores da alavancagem do desenvolvimento local; o ambiente e os bens culturais como fatores de desenvolvimento local por meio do turismo sustentável e da conservação do meio ambiente; a formação de consórcios de municípios para a implementação e a gestão de serviços e de políticas públicas locais para a promoção 
de micro e pequenas empresas e para o cooperativismo; a descentralização das políticas sociais como fator de participação, coesão social e desenvolvimento local.

Uma avaliação do conjunto dos projetos que integraram o Programa Brasil Próximo mostra que foram alcançados grande número dos objetivos propostos, sobretudo no que diz respeito à adoção, por parte dos territórios, de metodologias de concertação multinível e multiautorais (pactos territoriais), com o fortalecimento da capacidade das instituições locais de construir ações de intervenção e planejamento regional de forma participativa. Disseminou-se, também, uma nova abordagem de políticas sociais que, tendo o pacto territorial como instrumento de concertação participativa, integrou programas federais, estaduais e municipais,

Foram criados, ainda, laços profundos entre os territórios brasileiros e italianos envolvidos (entre Ùmbria e os Municípios do Centro Paulista e os da Região da Campanha; entre Marche e Toscana e as regiões do Piauí, da Baixada Fluminense e da Mantiqueira; entre Emilia Romagna e a Paraíba e o Paraná; entre Ligúria e Amazonas), por meio de ações articuladas de intercâmbio, de atividades em campo e de transferência de know-how entre os territórios não apenas em termos cognitivos, mas, sobretudo na práxis.

Uma outra perspectiva de avaliação do Programa é aquela que desvia o olhar para os principais legados dos projetos e para o potencial de perpetuação da lógica de desenvolvimento inculcada durante o período em que as ações estiveram em curso. Nessa perspectiva as inferências passíveis de serem apontadas com base na pesquisa não são muito promissoras. Os resultados obtidos oferecem fortes evidências de que, se por um lado o Programa produziu fortes efeitos pedagógicos, disseminando valores e as implícitas práxis da concepção contemporânea do desenvolvimento, por outro, a diversidade das realidades locais revela limites e dificuldades para o prosseguimento dos processos disparados.

Nos casos do Piauí e da Baixada Fluminense, conhecidos como áreas de risco do ponto de vista social e econômico, os projetos, implementados mais por decisões externas do que por iniciativas endógenas, não sustentaram as propostas sem o apoio externo, seja dos parceiros italianos ou mesmo do governo brasileiro. No Piauí, tendo partido de um projeto já em curso na área do Parque Nacional da Serra das Confusões, a atuação do Programa Brasil Próximo impulsionou a cooperação no território, com intensa participação da equipe 
técnica italiana e de representantes dos municípios parceiros e com forte apoio governamental. Contudo, o encerramento do projeto e o fim do apoio internacional trouxeram forte redução nas atividades e possibilidades de continuidade, face à extrema pobreza e precariedade da região e a descontinuidade do apoio estadual.

Caso semelhante ocorreu na Baixada Fluminense. 0 projeto estruturou-se a partir de atividades de ONGs existentes na região, com apoio de instituições federais (Ministério do Desenvolvimento Social e de Políticas para a Juventude) e das prefeituras dos municípios integrantes do território. As ações do projeto possibilitaram a coleta e a sistematização de completo levantamento sobre grupos e equipamentos culturais na região, visando à ulterior construção de políticas públicas territoriais de incentivo à arte e cultura. Com o encerramento do projeto e o escasseamento dos financiamentos externos (italianos e do governo federal), a continuidade das ações ficou dependente das parcas e improváveis possibilidades de apoio das administrações municipais, tendo, ao fim e ao cabo, retornado à esfera de ação das ONGs já anteriormente envolvidas.

No caso do Alto Solimões, o processo e os legados ocorreram de forma oposta aos dos dois casos anteriores, dado que as iniciativas promotoras do desenvolvimento territorial e da cooperação não estavam presentes no território antes do Programa Brasil Próximo e a sobrevivência da experiência foi assegurada e persiste graças à manutenção do apoio do Governo do Estado do Amazonas, da Diocese local e de entidades civis locais, criadas ou fortalecidas no percurso do projeto.

Em Curitiba, o Programa Brasil Próximo apoiou-se em projetos já financiados e incentivados pelo SEBRAE PR, os quais permaneceram ativos, movidos pelas parcerias com produtores locais. Houve significativa mudança cultural com a organização do Centro de Abastecimento Municipal, com a obtenção de certificações e a redução de perdas no transporte de produtos da agricultura familiar para o Centro de Abastecimento. No caso de Campina Grande, apesar do forte apoio inicial de SEBRAE, o projeto da produção de algodão colorido, não teve grande alcance e deixou poucos resultados no território.

Na região da Campanha gaúcha, os legados do Programa Brasil Próximo foram muito significativos, principalmente pelo conteúdo de inovação e aprendizado técnico presente na produção da olivicultura incentivada no território. Assim, tendo agregado conhecimento à região e aos pequenos produtores locais, as ações implementadas pelo projeto tendem a 
prosseguir consolidando as atividades da pequena agricultura familiar frente à grande olivicultura presente desde sempre na região.

O projeto na Serra da Mantiqueira também foi bastante significativo, na perspectiva de seu legado político e técnico para os municípios da região. A criação da marca "Território Mantiqueira", nova expressão da ADITIM - Associação de Turismo do Território Mantiqueira, evidencia que a qualificação pretendida durante o Programa Brasil Próximo deixou um importante legado ao território, fortalecendo-o e consolidando-o como pólo turístico.

No território denominado Centro Paulista, composto por oito municípios, o legado do projeto restringiu-se aos municípios de Rio Claro e Jaú, o primeiro voltado à agricultura familiar e o segundo ao segmento da indústria de calçados, nos quais houve parcerias entre prefeituras e entidades. Em Rio Claro, o apoio prestado pela prefeitura possibilitou a transformação de uma associação local em cooperativa de pequenos agricultores, além da criação do "Selo Brasil Próximo" de agricultura regional. O posterior ingresso do município e seu entorno territorial no projeto Territórios da Cidadania do Governo Federal vem assegurando a continuidade das ações propostas pelo Programa Brasil Próximo.

\section{Considerações finais}

Uma primeira conclusão, passível de ser extraída com base nos resultados da pesquisa, é a de que a cooperação internacional para o desenvolvimento, preconizada pelo Programa Brasil Próximo, se mostrou apenas parcialmente exitosa. Isso porque, se de um lado as ações de cooperação descentralizada se revelaram conformes aos pressupostos expressos na literatura, (Douxchamps, 1996; Romero, 2010; Haftek, 2003), notadamente no que diz respeito às interações entre ambos os lados, de outro, os efeitos finais das ações, a promoção do desenvolvimento nos territórios, foram apenas parciais e limitados. Sugere-se, com isso, que o Programa tenha alcançado seus propósitos quanto aos meios utilizados sem, no entanto, lograr êxito quanto aos fins, salvo as exceções apontadas na seção anterior. As razões para as relatadas disparidades de resultados encontram amplo respaldo na literatura, porquanto nos três territórios em que os resultados foram mais favoráveis 
ocorreram três fatores cruciais: a efetiva transferência de conhecimentos (dos parceiros italianos às comunidades locais); a criação e/ou o fortalecimento de redes locais de agentes; o intenso envolvimento, durante e após a implementação das ações, dos governos locais/regionais.

Esse conjunto de constatações sugere uma segunda conclusão de caráter mais geral, qual seja a de que a cooperação descentralizada, horizontal, não promove o desenvolvimento local, mas sim aporta fatores e condições, frágeis ou inexistentes nos territórios, passíveis de serem apropriados pelos agentes locais que, por esses meios, se capacitam a promover o desenvolvimento em seus respectivos âmbitos locais.

Uma terceira conclusão, com foco na concepção do Programa, é que o mesmo não operou de forma sistêmica, mas sim de forma grandemente fragmentária, tanto da parte do governo italiano quanto do brasileiro: cada um dos oito projetos foi conduzido por equipes que não dialogaram entre si; não houve troca de experiências; não houve qualquer tipo de visão do todo e de integração, que propiciassem retroalimentações internas, ajustes e efeitos sinérgicos.

Finalmente, quanto à pesquisa, em sua proposta metodológica, pode-se concluir que tenha alcançado êxito, tanto no seu propósito exploratório quanto no descritivo e ainda nas contribuições para a literatura e para a teoria.

Tais contribuições, sobretudo no que diz respeito ao olhar para o futuro, poderão se expressar e materializar em referenciais, sobretudo analíticos, para o estudo de programas similares, no Brasil ou fora, que venham a comportar ações diversas em territórios distintos, realizadas ao abrigo de uma iniciativa estatal centralizada, preferencialmente no formato de cooperação com parceiro internacional.

\section{Referências bibliográficas}

ABRAMOVAY, R. (1998). Agriculture familiale et développement territorial au Brésil. Ruralia - Revue de I'Association des ruralistes français ARF, 1 (3): 91-112.

ABRAMOVAY, R. (2000). O capital social dos territórios: repensando o desenvolvimento rural. Economia Aplicada, 4: 379-397. 
ABRAMOVAY, R. (2002). Agricultura familiar y desarrollo territorial. Reforma agrária - FAO, 1: 28-43.

ABRAMOVAY, R. (2007). Para uma teoria dos estudos territoriais. In A. C. Ortega \& N. Almeida Filho (Orgs.). Desenvolvimento territorial, segurança alimentar e economia solidária. Campinas: Alínea, 19-38.

ALBAGLI, S. \& MACIEL, M. L. (2004). Informação e conhecimento na inovação e no desenvolvimento local. Ciência da Informação, 33(3): 9-16.

ALMEIDA, M. G. de. (2004). Desenvolvimento turístico ou desenvolvimento local? Algumas reflexões. Anais do Encontro Nacional de Turismo de Base Local - ENTBL.

AMARAL FILHO, J. do. (2001). A endogeneização no desenvolvimento econômico regional e local. Planejamento e Políticas Públicas, 23: 261-286,.

ANDION, C. (2003). Análise de redes e desenvolvimento local sustentável. Revista de Administração Pública, 37 (5): 1033-1054,.

BARBOSA, F. F. (2005). O tursimo como um fator de desenvolvimento local e/ou regional. Cadernos de Geografia 10(14): 107-114.

BARGE-GIL, A. (2010). Cooperation-based innovators and peripheral cooperators: An empirical analysis of their characteristics and behavior. Technovation, 30: 195-206.

BARQUero, A. V. (1993). Politica económica local: la respuesta de las ciudades a los desafios del ajuste productivo. Madri: Pirámide.

BLANCO, E. S. (2004). O turismo rural em áreas de agricultura familiar: a "novas ruralidades" e a sustentabilidade do desenvolvimento local. Caderno Virtual de Turismo, 4(3): 44-49.

BONNAL, P. \& MALUF, R. S. ( 2010). Políticas de desenvolvimento territorial e multifuncionalidade da agricultura familiar no Brasil. Politica \& Sociedade, 8: 211-250.

BRASIL PRÓXIMO. (2010) Programa descentralizado de cooperação Brasil-Itália, experiências e resultados, 2003/2010. Documento da Secretaria Geral da Presidência da Republica. Brasil.

BRASIL PRÓXIMO. (2015) Programa descentralizado de cooperação Brasil-Itália, experiências e resultados, 2010/2015. Documento da Secretaria Geral da Presidência da Republica. Brasil.

BRASIL PROXIMO. (2016). Brasil Próximo: cinque regioni italiane per lo sviluppo integrato in Brasile. Disponível em: <http://www.brasilproximo.com/?page_id=19>. Acesso em: 19 maio 2017.

BUARQUE, S. C. (2008) Construindo o desenvolvimento local sustentável: metodologia de planejamento. Rio de Janeiro: Garamond.

BURITY, J. (2007). Cultura e desenvolvimento. In G. M. Nussbaumer (org.). Teorias e políticas da cultura: visões multidisciplinares. Salvador: Edufba.

CAMPOS, R. R.; CÁRIO, S. F.; NICOLAU, J. A. \& VARGAS, G. (2002). Aprendizagem por interação: pequenas empresas em sistemas produtivos e inovativos locais. Universidade Federal do Rio de Janeiro: Instituto de Economia.

CASSIOLATO, J. E. \& SZAPIRO, M. (2002). Arranjos e sistemas produtivos e inovativos locais no Brasil. Universidade Federal do Rio de Janeiro: Instituto de Economia.

CASTELLS, M. (1999). A sociedade em rede. São Paulo: Paz e Terra.

COSTA, F. de A. (2006). Arranjos e sistemas produtivos e inovativos locais - as possibilidades do conceito na constituição de um sistema de planejamento para a Amazônia. Revista Brasileira de Inovação, 5(1): 77-98.

CRUZ, G. M. \& PULIDO-FERNÁNDEZ, J. I. (2012). Interorganizational relational dynamics for tourism development. Cases of Villa Gesell and Pinomar (Argentina). Revista de Estudios Regionales, 94: 167-194.

DOUXCHAMPS, F. (1996.). Decentralized cooperation: a new European approach at the service of participatory development - methodological study. Bruissels: COTA.

ERBER, F. S. (2008). Eficiência coletiva em arranjos produtivos locais industriais: comentando o conceito. Nova Economia, 18(1): 11-32. 
ESPARCIA, J.; ESCRIBANO, J. \& SERRANO, J. J. (2016). Una aproximación al enfoque del capital social y a su contribución al estudio de los procesos de desarrollo local. Investigaciones Regionales - Journal of Regional Research, 34: 49-71.

ETZKOWITZ, H. (2004). The evolution of the entrepreneurial university.International Journal of Technology and Globalization, 1(1): 64-77.

ETZKOWITZ, H. \& LEYDESDORFF, L. (2000). The dynamics of innovation: from National Systems and "Mode 2" to a Triple Helix of university-industry-government relations. Research Policy, 29:109-123.

FARAH, M. F. S. (2001). Parcerias, novos arranjos institucionais e políticas públicas no nível local de governo. Revista de Administração Pública, 35(1): 119-144.

FISCHER, T. (2002). Poderes locais, desenvolvimento e gestão - introdução a uma agenda. In T. FISCHER (org.) Gestão do desenvolvimento e poderes locais: marcos teóricos e avaliação. Salvador: Casa da Qualidade, 344 p.

FISCHER, T. \& MELO, V. P. (2004). Organizações e interorganizações na gestão do desenvolvimento territorial. Organizações\&Sociedade, 11: 13-41.

FORSMAN, H. (2009). Improving innovation capabilities of small enterprises: cluster strategy as a tool. International Journal of Innovation Management, 13 (2): 221-243.

FREY, K. (2003). Desenvolvimento sustentável local na sociedade em rede: o potencial das novas tecnologias de informação e comunicação. Revista de Sociologia e Política, 21: 165-185.

FROEHLICH, J. M. (2000). Turismo rural e agricultura familiar: explorando (criticamente) o cruzamento de abordagens e estratégias para o desenvolvimento local. In J. ALMEIDA \& M. RIEDL(Orgs.). Turismo rural: ecologia, lazer e desenvolvimento. Bauru: EDUSC.

GALDÁMEZ, E. V. C.; CARPINETTI, L. C. R. \& GEROLAMO, M. C. (2009). Proposta de um sistema de avaliação do desempenho para arranjos produtivos locais. Gestão \& Produção, 16(1):133-151.

GOMES, A. F. O. (2005). empreendedorismo como uma alavanca para o desenvolvimento local. Revista Eletrônica de Administração, 4 (2): 1-14.

GORGULHO, L. F.; GOLDENSTEIN, M.; ALEXANDRE, P. V. M. \& MELLO, G. A. T. de. (2009). Economia da cultura, o BNDES e o desenvolvimento sustentável. BNDES Setorial, 30: 299-355.

GRIMPE, C.; SOFKA, W. (2009). Search patterns and absorptive capacity: low- and high-technology sectors in European countries. Research Policy, 38: 495-506.

GORDACH, C. (2013). Cultural economy planning in creative cities: discourse and practice. International Journal of Urban and Regional Research, 37(5): 1747-1765.

HAFTEK, P. (2003). An introduction to decentralized cooperation: definitions, origins and conceptual mapping. Public Administration and Development, 23 (4):333-345.

HAUSMAN, A. (2005). Innovativeness among small businesses: theory and propositions for future research. Industrial Marketing Management, 34: 773-782.

HEIDENREICH, M. (2009). Innovation patterns and location of European low- and medium-technology industries. Research Policy, 38: 483-494.

IACONO, A. \& NAGANO, M. S. (2007). Uma análise e reflexão sobre os principais instrumentos para o desenvolvimento sustentável dos arranjos produtivos locais no Brasil. Revista Gestão Industrial, 3(1): 37-51.

IRVING, M. DE A. \& SANCHO, A. P. (2005). Revisitando significados em sustentabilidade no planejamento turístico. Caderno Virtual de Turismo, 5(4): 1-7.

KASHIMOTO, E. M.; MARINHO, M. \& RUSSEF, I. (2002). Cultura, identidade e desenvolvimento local: conceitos e perspectivas para regiões em desenvolvimento. Interações, 3(4): 35-42.

KAUFMANN, A. \& TÖDTLING, F. (2002). How effective is innovation support for SMEs? An analysis of the region of Upper Austria.Technovation, 22(3): 147-159.

KIRNER, E.; KINKEL, S. \& JAEGER, A. (2009). Innovation paths and the innovation performance of lowtechnology firms: an empirical analysis of German industry. Research Policy, 38: 483-494. 
LASTRES, M. H.; CASSIOLATO, J. E. (2003). Novas políticas na era do conhecimento: o foco em arranjos produtivos e inovativos locais. Parcerias Estratégicas, 8(17): 5-29.

LAYRARGUES, P. P. (1997). Do ecodesenvolvimento ao desenvolvimento sustentável: evolução de um conceito? Proposta, 24(71): 1-5.

LEHTONEN, M. (2004). The environmental-social interface of sustainable development: capabilities, social capital, institutions. Ecological Economics, 49(2): 199-214.

LEITE, S. P. (2002). Agricultura familiar e experiências inovadoras no semi-árido nordestino. Estudos Sociedade e Agricultura (UFRJ), 18: 180-184.

LEITE, S. P. (2004). Multifonctionnalité et stratégies de reproduction familiale à partir de l'analyse de budgets domestiques. Quelques indications sur les 'assentamentos' ruraux dans l'agriculture brésilienne. Les Cahiers de la Multifonctionnalité, 7: 55-70.

LORENZO, H. C.; FONSECA, S. A. \& SAMPAIO, M. C. (2016). Programa Brasil Próximo no contexto da cooperação internacional descentralizada entre o Brasil e a Itália. Revista Espacios, 37: 21-32.

LÓSSIO, R. A. R. \& PEREIRA, C. M. (2007). A importância da valorização da cultura popular para o desenvolvimento local. Anais do Terceiro Encontro de Estudos Multidisciplinares sobre Cultura - III ENECULT.

MALECKI, E. J. (2007). Cities and regions competing in the global economy: knowledge and local development policies. Environment and Planning C: Government and Policy, 25 (5): 638-654.

MARRA, M. (2012). What coordination mechanisms work to manage regional development programmes? Insights from Southern italian regions. European Urban and Regional Studies, 21(3): 254-227.

MBAH, M. F. (2016). Towards the idea of the interconnected university for sustainable community development. Higher Education and Research Development, 35(6): 1228-1241.

MEDEIROS, E. (2016). Is there a rise of the territorial dimension in the EU cohesion policy? Finisterra, LI, 103: 89-112.

MELLO, J. M. C. de. (2004). A abordagem Hélice Tríplice e o desenvolvimento regional. Anaisdo Seminário Internacional Empreendedorismo, Pequenas e Médias Empresas e Desenvolvimento Local.

MICHAEL, H. \& BETH, P. (2004). Universities, localities and regional development: the emergence of the 'Mode 2' University? International Journal of Urban and Regional Research, 28(1): 212-223.

MOREIRA, S. B. \& CRESPO, N. (2011). Sobre a natureza multidimensional do desenvolvimento. In: Homenagem ao Professor Doutor Adelino Torres. Lisboa: Almedina: 818-838.

MOULAERT, F.; MARTINELLI, F.; SWYNGEDOUW, E. \& GONZÁLES, S. (2005).Towards alternative model(s) of local innovation. Urban Studies, 42(11): 1969-1990.

MOULAERT, F.; NUSSBAUMER, J. (2005). The social region: beyond the territorial dynamics of the learning economy. European Urban and Regional Studies, 2(1): 45-64.

MULS, L. M. (2008). Desenvolvimento local, espaço e território: o conceito de capital social e a importância da formação de redes entre organismos e instituições locais. Revista EconomiA, 9(1): 1-21.

NEVES, C. E. B. \& NEVES, F. M. (2006). O que há de complexo no mundo complexo? Niklas Luhmann e a Teoria dos Sistemas Sociais. Sociologias, 8(15): 182-207.

NOOTEBOOM, B. (1994). Innovation and diffusion in small firms: theory and evidence. Small Business Economics, 6: 327-347.

NORONHA, E. G. \& TURCHI, L. (2005). Política industrial e ambiente institucionais na análise de Arranjos Produtivos Locais. Brasília: IPEA - Texto para discussão no 1076: 1-33.

NUNES, P. M.; SERRASQUEIRO, Z. \& LEITÃO, J. (2012). Is there a linear relationship between R\&D intensity and growth? Empirical evidence of non-high-tech vs. high-tech SMEs. Research Policy, 41: 36-53.

OLAVE, M. H. L. \& AMATO NETO, J. (2001). Redes de cooperação produtiva: uma estratégia de competitividade e sobrevivência para pequenas e médias empresas. Gestão \& Produção, 8(3): 289-303. 
PIQUET, R. (1993). Reestruturação do espaço regional e urbano no Brasil: o poder do Estado e dos grandes investimentos. Rio de Janeiro: IPPUR - UFRJ.

POTTER, R.; BINNS, T.; ELLIOTT, J. A.; NEL, E. \& SMITH, D. W. (2018). Geographies of development: an introduction of development studies. Abingdon; New York: Routledge.

RADAS, S. \& BOZIC, L. (2009). The antecedents of SME innovativeness in an emerging transition economy.Technovation, 29: 438-450.

RATNER, B. D. (2004). "Sustainability" as a dialogue of values: challenges to the sociology of development. Sociological Inquiry, 74(1): 50-69.

REIS, A. C. F. Economia da cultura e desenvolvimento sustentável: o caleidoscópio da cultura. Barueri: Manole, 2007, 340 p.

ROMERO, M. D. H. (2010). Aportes de la cooperación descentralizada Unión Europea-América Latina a la cooperación territorial en América Latina: elementos para el debate. In: Anuario de la Cooperación Descentralizada. Observatorio de Cooperación Descentralizada Unión Europea - America Latina, 23 p.

ROVER, O. J. (2011). Obstáculos e exigências para a governança regional. Revista Brasileira de Gestão e Desenvolvimento Regional, 7(1): 130-152.

ROTHWELL, R. (1984). The role of small firms in the emergence of new technologies.Omega: the International Journal of Management, 12 (1): 19-29.

SACHS, I. (2002). Caminhos para o desenvolvimento sustentável. Rio de Janeiro: Garamond.

SANTOS A. M. \& MITJA D. (2012). Agricultura familiar e desenvolvimento local: os desafios para a sustentabilidade econômico-ecológica na comunidade de Palmares II, Parauapebas, PA. Interações, 13(1): 3948.

SAQUET, M. A. (2011). O desenvolvimento numa perspectiva territorial, multidimensional e Democrática. Resgate, 19 (21): 5-15.

SCIPIONI, A.; MAZZI, A.; MASON, M. \& MANZARDO, A. (2009). The Dashboard of Sustainability to measure the local urban sustainable development: The case study of Padua Municipality. Ecologic Indicators, 9(2): $364-380$.

SIENKIEWICZ, M. W. (2014). Local economic development in Poland: determinants and outcomes. EkonomskuTeoriju i Praksu, 32(2): 405-427.

SILVA, A. S.; BABO, E. P. \& GUERRA, P. (2013). Cultural policies and local development: the portuguese case. Portutuese Journal of Social Science: 113-132.

SOBOL, A. (2008). Governance barriers to local sustainable development in Poland.Management of Environmental Quality: An International Journal, 19(2): 194-203.

SONOBE, T. \& OTSUKA, K. (2015). Cluster-based MSE development: the role of kaizen training. The Pakistan Development Review, 54(4): 609-626.

SOTO, L. (1997). Local development challenge: a discussion agenda in Latin America. Revista Venezolana de Gerencia, 2(4): 169-181.

UHLMANN, G. W. (2002). Teoria Geral dos Sistemas: do atomismo ao sistemismo. São Paulo: Instituto Siegen.

WOOD, A. M.; WATTS, H. D. \& WARDLE, P. (2004). Growth-oriented small firms and the nature and extent of local embeddedness: the case of a traditional metalworking cluster. Growth and Change, 35(4): 419-433.

ZANON, B. (2014). Local development in fragile areas: re-territorialization processes in an alpine community. International Planning Studies, 19: 335-358. 